\title{
Smart Garbage Collection and Dumping System using NI myRIO and Arduino
}

\author{
M. Srilatha, D. Nagajyothi, V. Jyothi
}

\begin{abstract}
The key issue in waste management system to ensure healthy environment is Garbage Collection and Dumping In traditional method, at public places garbage bins are placed to collect the garbage, which is usually collected by the garbage collection truck with the help of employed personnel and will be sent to the dumping yard to dump the collected garbage. These bins overflowed frequently before the routine maintenance takes place, which leads to bad order and unhygienic environment causing various life-costing diseases. As this problem is increasing day-by-day, an automated system for effective waste management system is desired which can collect garbage timely without human involvement is proposed and is implemented using NI myRIO, Arduino UNO and NI LabVIEW software. The proposed system consists of two main sub systems- Big Bin and small bin. Big bin moves in a regular predefined path marked as black line in regular time intervals to collect garbage from Small Bins placed in different locations. The proposed system is capable to automate the entire garbage collection and dumping process to ensure healthy environment.
\end{abstract}

Keywords : myRIO, LabVIEW, Arduino UNO, Waste Management, Garbage Collection and Garbage dumping, IR Sensors.

\section{INTRODUCTION}

Automation was initially introduced in industries to perform specific tasks and now it is widely being used in almost all areas including performing daily household activities. Automation reduces burden on the human beings in terms of amount of time and efforts spent on the work ultimately reducing the effective cost of the work / output. The immediate need of addressing waste management can be solved using the automation of waste management. Collection and disposal of garbage is a quite hectic process for the community. While considering human health, hygiene and environmental cleanliness, the effectiveness of garbage collection and dumping is very important. The traditional way of garbage collection and dumping using garbage bins

Revised Manuscript Received on December 30, 2019.

* Correspondence Author

M. Srilatha*, Department of Electronics and Communication Engineering, Vardhaman College of Engineering, Hyderabad, Telangana State, India.

D. Nagajyothi, Department of Electronics and Communication Engineering, Vardhaman College of Engineering, Hyderabad, Telangana State, India.

V. Jyothi, Department of Electronics and Communication Engineering, Vardhaman College of Engineering, Hyderabad, Telangana State, India.

(C) The Authors. Published by Blue Eyes Intelligence Engineering and Sciences Publication (BEIESP). This is an open access article under the CC BY-NC-ND license (http://creativecommons.org/licenses/by-nc-nd/4.0/) and bags manually has become a highly time taking, difficult and unhygienic process.

Garbage collection and dumping should be handled with utmost care to ensure the environmental safety and the health of people living around. But, due to the busy life style of people and negligence of personnel / government agencies concerned, garbage collection and dumping is not properly handled particularly in some of the countries / areas. While adopting new technology, proper garbage collection and dumping system can be established for heavily crowded places like hospitals, schools, parks, hotels, production plants, offices, tourist places and etc., where garbage gets accumulated quickly and hazardous. Garbage is detected first by using ultrasonic sensor and the same is informed to municipal people by GSM system [1]. Garbage monitoring and informing system is implemented using IOT [2]-[3], where Raspberry Pi and ultrasonic sensor is used to monitor the status of the garbage in the bins and the same will be modernized to GHMC through an application (GUI). Once the garbage crosses the level, municipal workers will clean the bins. Best-sought solution for this is introducing automated garbage collection and dumping system [4]. The Robo-dumpster, one of the existing automated system which collects garbage from filled garbage cans and dumps them at identified area. Similarly, Dust Cart is another automated system, which move through urban areas collecting garbage door to door and it is capable enough to avoid static and dynamic obstacles. Robot is used to collect garbage automatically without human intervention [5]-[7] is designed. However, the above specified automated systems and other existing systems has major disadvantages like high cost in developing and maintenance, complicated functioning. These existing systems mainly focus on collecting filled garbage bins while ignoring some of the important parameters like mechanism to be adopted while collecting the garbage and etc. The efficiency and effectiveness of the entire garbage collection and dumping system depends on an important factor path planning [8]. Apart from the above two existing systems, a simple sensor based alert system also proposed [9] earlier, which could give alert signal, to the maintenance server for instant cleaning of garbage bins with a proper automated verification and authentication system depending on the level of garbage filled in the garbage bin. Another alternative method for implementation of the garbage collection and dumping system is IoT based embedded system using Radio-Frequency Identification (RFID), Sensors, Arduino controller and GSM attached to a solid garbage bin and carrying vehicle (preferably truck) monitoring system with real time performance monitoring environment. 
Internet based applications including the mobile compatible applications are developed for establishing interface between maintenance server and concerned maintenance personnel [10]-[12]. Proposed method (Automated Garbage Collection and Dumping System) in this paper focuses on collecting and dumping garbage with the help of path planning. This system uses two types of garbage bins; Small Bins which are placed in static locations to collect garbage, Big Bin equipped to a movable platform. Big bin will move in its predefined path which is marked using a black line and collect garbage gathered in small bins in regular intervals. Whenever the big bin gets filled it moves to a predefined dumping yard location directly and dump the garbage without any human interference. The big bin is controlled by NI myRIO [14] supported by NI LabVIEW [13] programming and small bins are controlled by Arduino UNO [15]. Path identification, small bins identification and dumping yard identification are done with the help of IR sensors. This system will provide solutions to the problems that are not addressed by the existing systems.

The remainder of this paper is organized as follows: Methodology of Garbage Collection and Dumping is discussed in Second section. Third section is described with the flowchart. Fourth section shows the results of the proposed systems' prototype model. Finally, fifth section concludes about proposed system. Future modifications like functional additions and hardware optimisation are also outlined.

\section{PROCEDURE FOR PAPER SUBMISSION}

\section{A. Block Diagram}

The methodology adopted for the proposed garbage collection and dumping system is depicted in Fig. 1. The automatic collecting big bin is designed to move over the predefined path (marked in black colour line) and collects the garbage from the small bins, which are implanted in the predefined path. The big bin automatically moves to dumping yard and dump the garbage collected from small bins. Once the big bin dumps the collected garbage, it will go back to collect the garbage from small bins. The small bins are mounted at a level, higher than the height of big bin and the small bin is equipped with a door at the bottom so that once the door opens the collected garbage will be easily transferred in to the big bin. Both the big bin and small bins are equipped with IR sensors and the arrival of big bin is identified by the small bin using this Infra-Red identification process. Once the big bin reaches and positioned exactly below the small bin the IR transreceiver of both the bins gets stimulated and garbage will be dumped in to the big bin. The proposed system block diagram is shown in Fig. 2.

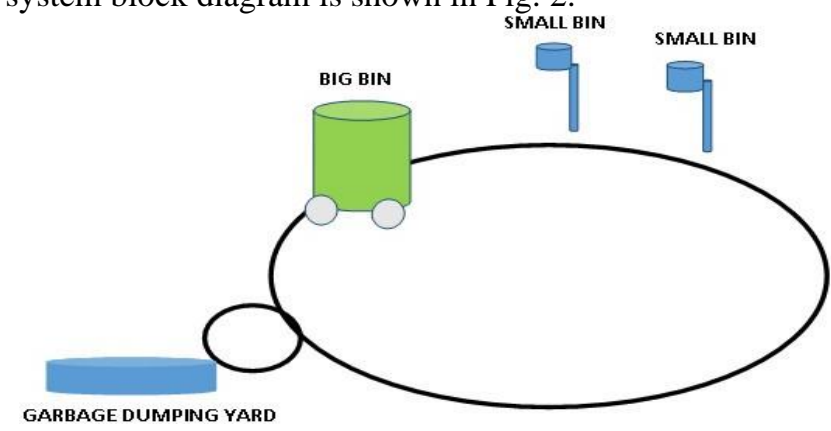

Fig. 1. Pictorial Representation of Proposed method

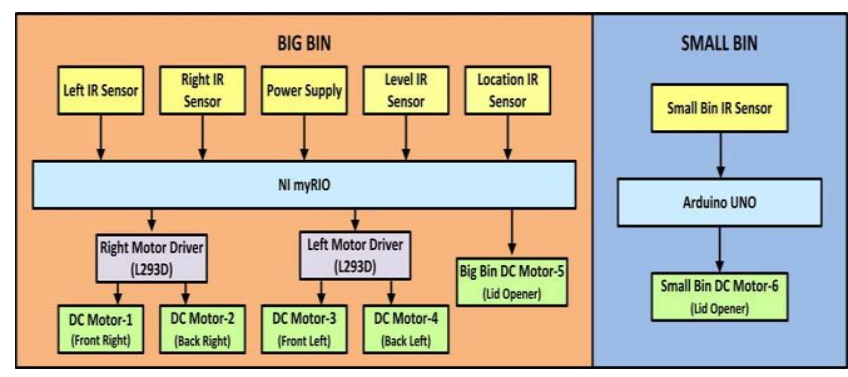

Fig. 2. Block Diagram of Garbage Collection and Dumping System

\section{B. Description}

Proposed system is represented in the block diagram as two parts namely big bin and small bin. The big bin functionality is controlled by NI myRIO, in addition it has four IR sensors. Left and Right IR sensors will help the big bin to identify the path to be followed, whereas Level IR sensor identify the threshold level of garbage collected in the bin. Once the garbage level in the big bin reaches to the threshold level then the big bin will get instruction to move to dumping yard. The forth sensor called Location sensor detects the small bins to collect the garbage and also dump yard to dump the garbage automatically. Four DC motors, DC motor-1 connect at the front right side, DC motor-2 connected at the back right side of the big bin, DC motor-3 connect at the front left side and DC motor- 4 connected at the back left side of the big bin, will make the big bin movable. These motors are driven by two motor drivers L293D, named Right Motor Driver to direct right side motors and Left Motor Driver to direct left side motors. The small bins functionality is controlled by Arduino UNO, each small bin has an IR sensor to detect the big bin. Once the big bin reach to small bin, with the help of a motor the lid at the bottom of the small bin opens and the garbage will be automatically transferred from small bin to the big bin. The connection diagram for the proposed system is shown in Fig. 3 and Fig. 4.

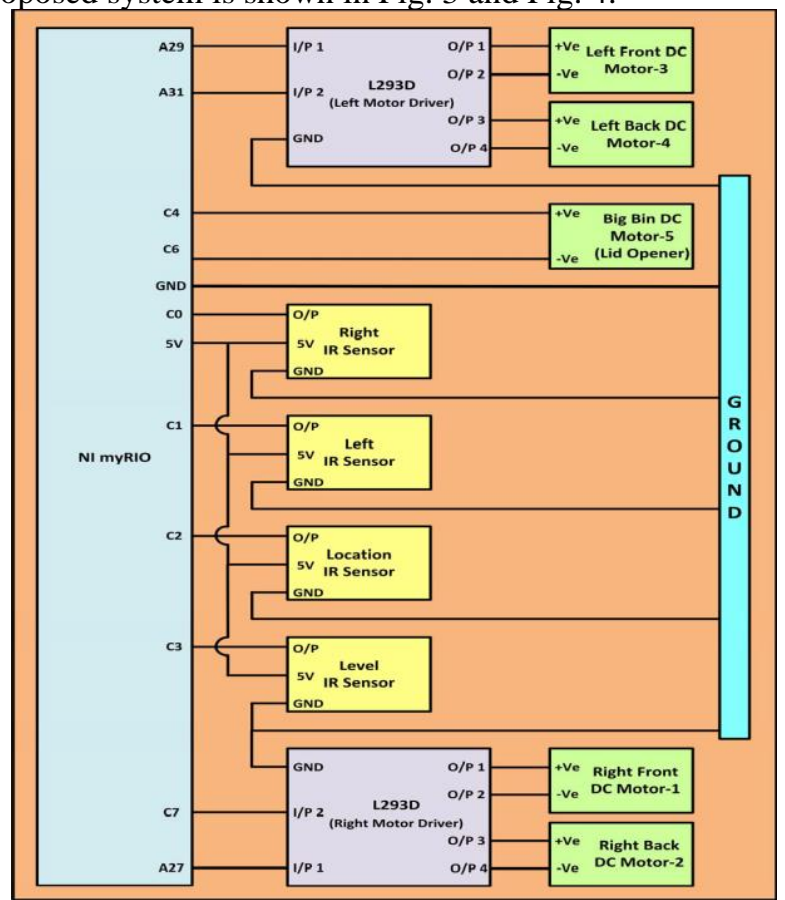

Fig. 3. Connection Diagram at Big bin 


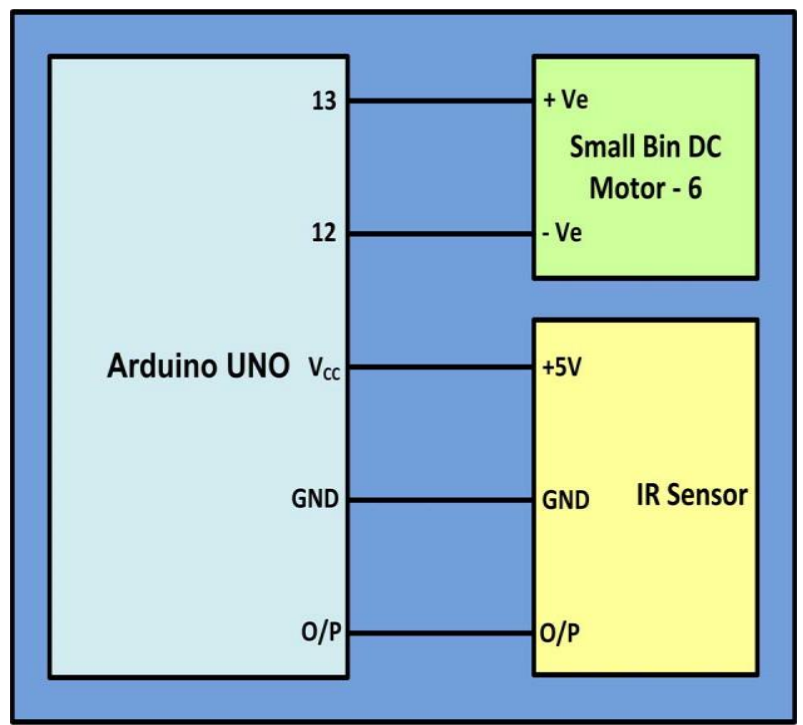

\section{FLOW CHART}

Fig. 5 shows design flow of Garbage Collection and Dumping System. In this system, three conditions to be performed are:

1) Is Big bin Level IR sensor exceeds the threshold point?

2) Is Big bin Location IR sensor sensed small bin / dumping yard?

3) Is Small bin IR sensor senses the Big bin?

Initially the system will verify for big bin right and left IR sensor signals, if no signal are sensed then, the big bin halts and wait for the signal.

If any one of the right or left IR sensor signal is received then the big bin turn in the direction of sensor signal received i.e., either right or left. If both the sensor signals are sensed (high) at the same time, then the big bin moves forward without turning. The big bin moves based on the signals received from IR sensors and a predefined path marked as a black coloured line.

In the next step, Whenever the IR sensor of small bin senses the location IR sensor of big bin then control signal will operate small bin DC motor-6, which is controlled by the Arduino. Whenever big bin reaches small bin it halts until small bin dumps the garbage in to the big bin and big bin continues its motion as per the marked path.

Garbage dumping is executed in two ways:

\section{A. Case 1}

Whenever the big bin reaches dumping yard, the big bin location IR sensor module senses and give high as output signal. Upon receiving high as output signal from location IR sensor the big bin lid gets opened and garbage collected from small bins will be dumped in the yard. Once the garbage is dumped out, lid gets closed and big bin goes back to the small bins to collect garbage.
Fig. 4. Connection Diagram at Small bin

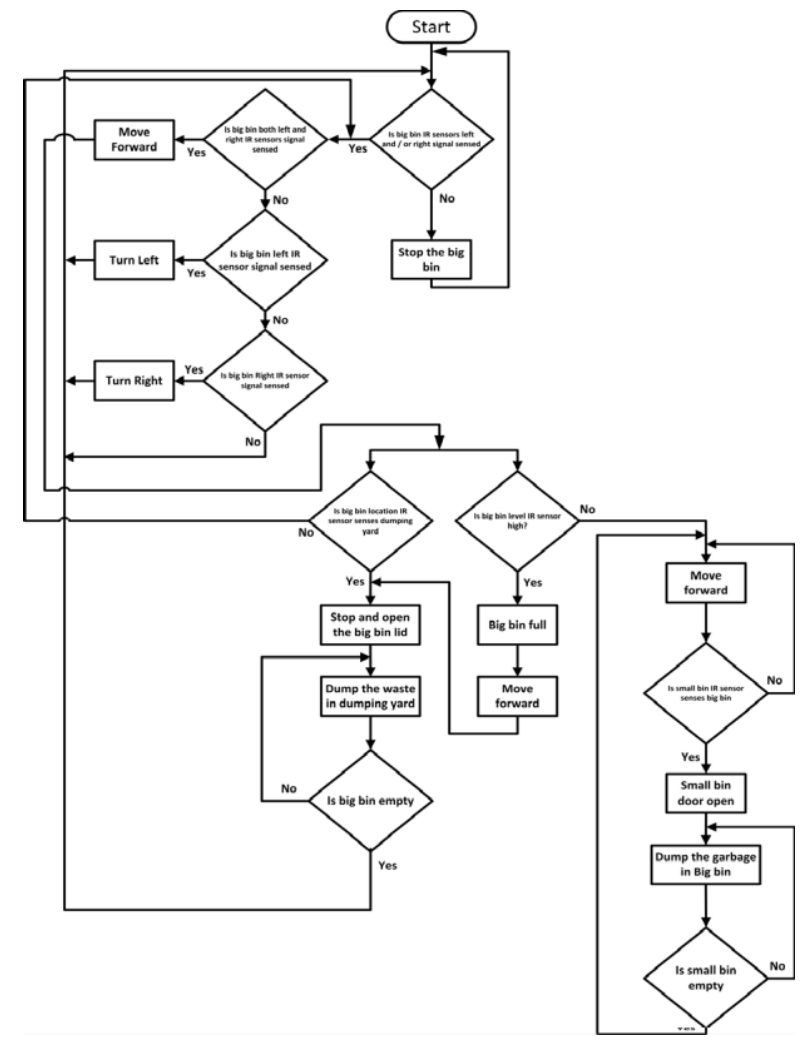

Fig. 5. Flowchart

B. Case 2

Whenever the garbage collected in the big bin reach threshold level, the level IR sensor give high as output signal. Once the output signal of level IR sensor turns to high, the big bin stops going to small bins (i.e., stops collecting garbage from small bins) and directly go to the dumping yard. Whenever the big bin reach dumping yard, the big bin Location IR sensor module senses and gives low as output signal and the collected garbage will be dumped in the yard. As soon as big bin gets empty the big bin again goes back to the small bins to collect he garbage.

\section{RESULTS \& DISCUSSION}

Fig. 6 shows the front panel of the garbage collection and dumping system implemented in LabVIEW software were it displays the Inputs and outputs as icons.

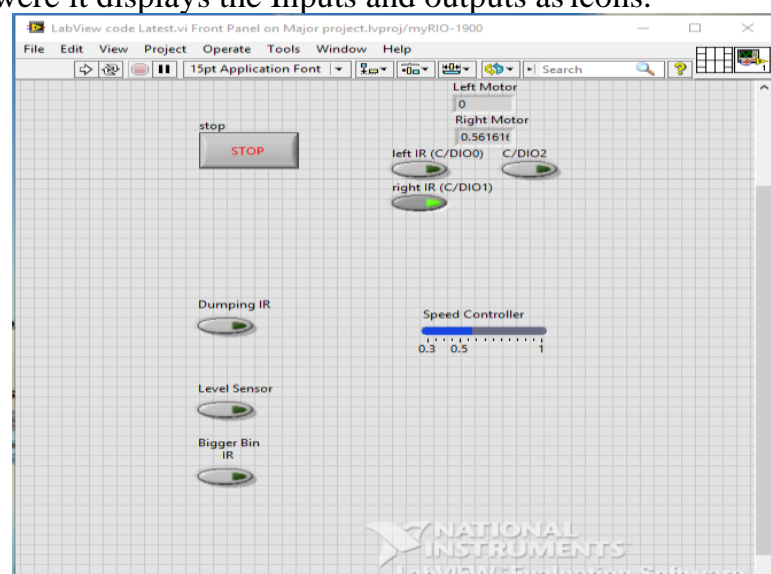

Fig. 6. Front panel of garbage collection and dumping system 
Fig. 7 shows the Vi block diagram in the case structure covering the basic conditions which are capable to handle all possible scenarios in the whole system functionality. The system functions based on big bin line follower IR Module which consists of right and left IR sensors. Depending on the signals received from the line follower module the big bin moves over the black line, which is used to, predefine the path to be followed by the big bin. Whenever the big bin reaches small bin, the big bin gets halts and positioned below the small bin and collect the garbage from the small bin. After collecting garbage from small bin it resumes to follow the predefined path to

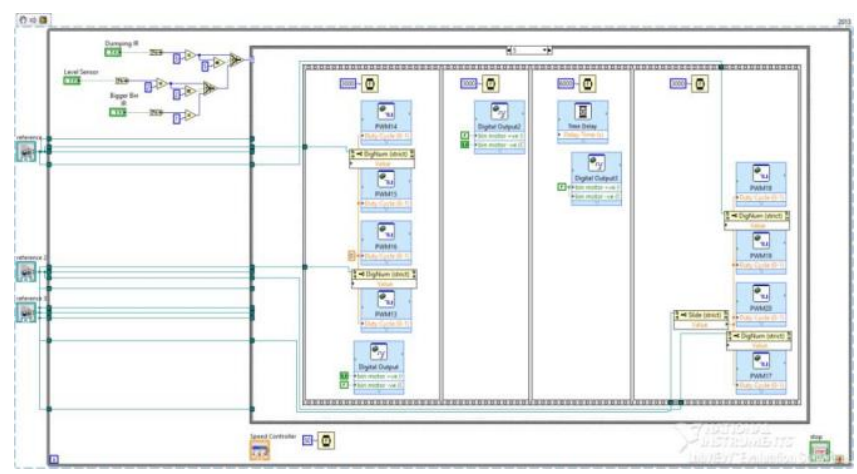

Fig. 7. Block Diagram of garbage collection and dumping system

reach the next small bin. This will be continued till the big bin reach dumping yard or the big bin level sensor senses the threshold level and routes the big bin directly to the dumping yard without collecting garbage from the remaining small bins in the path. Finally, upon reaching the dumping yard big bin Location IR sensor senses and lid is automatically opened and garbage is dumped in the yard.

\section{A. Line Follower IR module (left and right)}

Line follower IR module is equipped with two IR sensors one is right IR sensor and another is left IR sensor. These IR sensors are arranged in front side of the big bin to identify the predefined path marked as black line. Whenever the module is over the black line, the module gives high as output signal, otherwise it will give low as output signal. These output signals are fed as input signal to the system. Four different possible cases need to be handled based on the combination of signals received from the module.

\section{1)Default, Case1: No action takes place}

Whenever both IR sensors gives low as the output, the motor drives stop the system as shown in Fig 8 which is considered to be the default case.

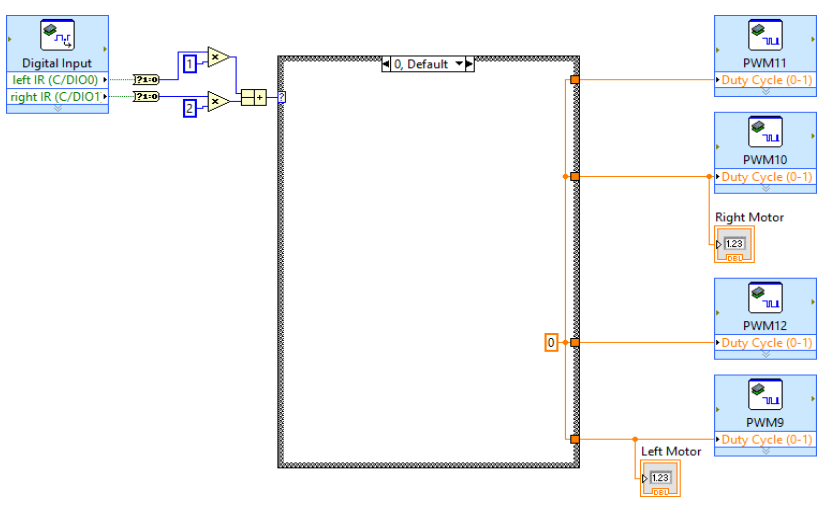

Fig. 8. Default case

2) Case 2: Left turn condition
In case 2, the left IR sensor gives high as output signal and right IR sensor gives low as output, the left and right motor drivers gives high input signal to the left motor and low input signal to the right motor respectively, making the big bin to take left turn which is represented in Fig. 9.

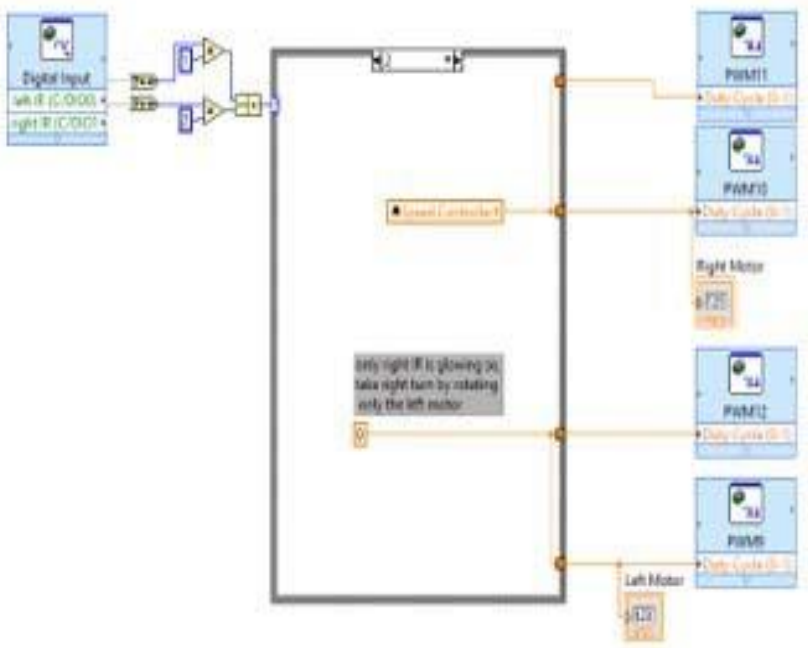

Fig. 9. Left turn condition

\section{3) Case 3: Right turn condition}

In case 3, the right IR sensor gives high as output signal and left IR sensor gives low as output signal, the right motor driver and left motor driver gives high input signal to the right motor and low input signal to the left motor respectively, making the big bin to take right turn which is represented in Fig. 10.

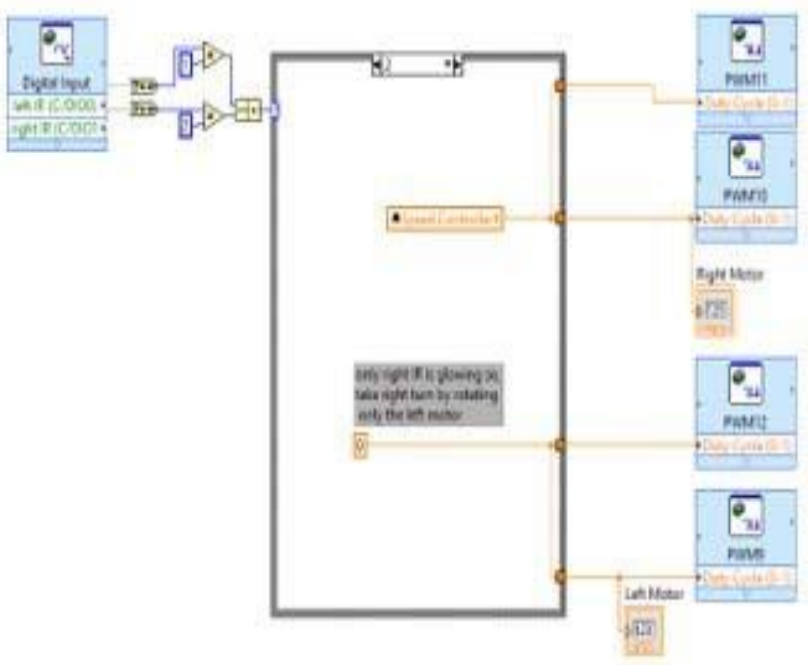

Fig. 10. Right turn condition

\section{4) Case 4: Move forward condition}

In case 4, both the Right and Left IR sensors gives active high as output to the system, to make the system move the big bin in forward direction by passing high to motor driver as shown in Fig. 11. 


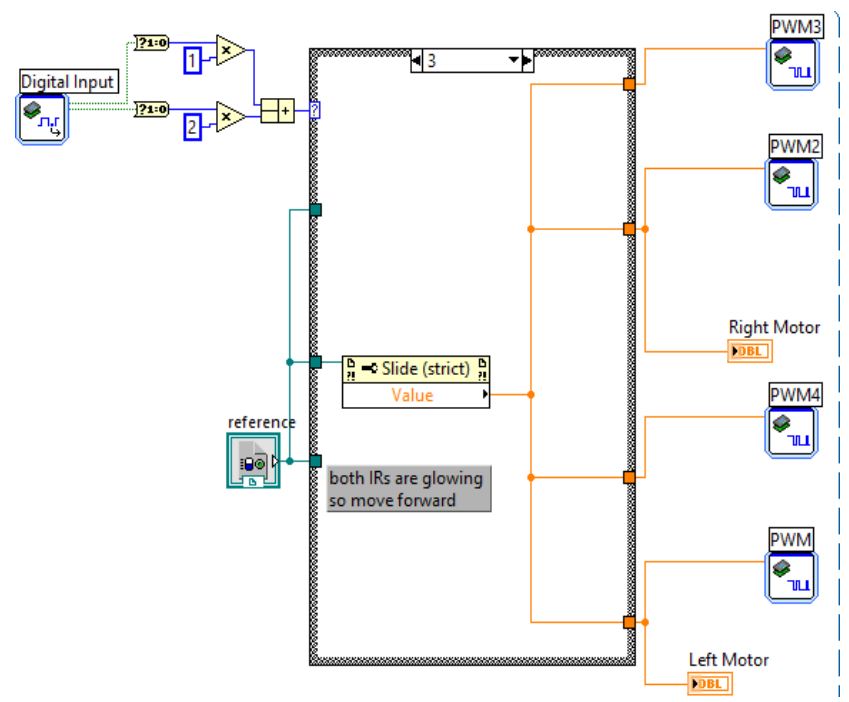

Fig. 11. Move forward condition

\section{B. Big bin encounters Small bin}

The big bin moves over the predefined path marked using the black line and whenever big bin encounters small bin it has to halt until the small bin dumps the garbage in to it and after that, it has to move in the predefined path. To sense the presence of small bin an IR sensor is connected at the top side of the small bin and big bin sensor is connected at the bottom side of the big bin. As soon as Big bin moves under small bin both the sensors gets activated and high is given as output signal. Upon receiving the high output from the sensors, DC motor- 6 of small bin operates and small bin lid (at the bottom of the small bin) will be opened to drop the garbage from small bin to big bin as shown in Fig. 12.

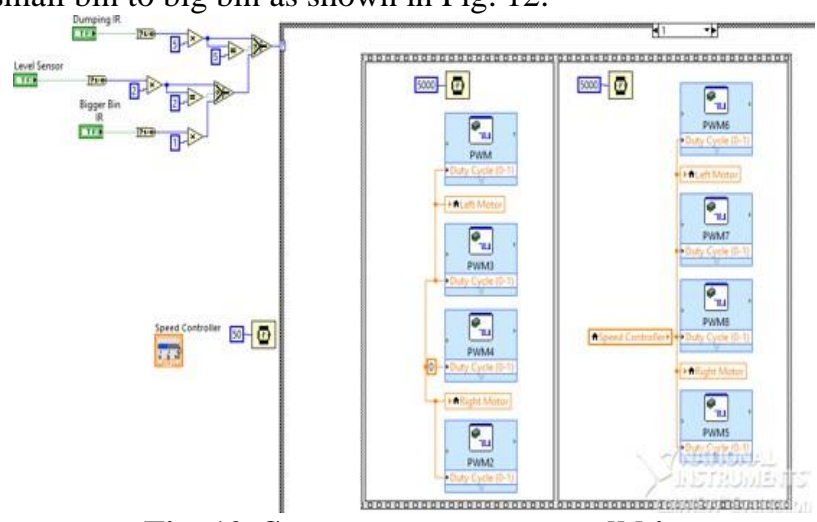

Fig. 12. System encounters small bin

\section{Big bin encounters Dumping yard}

\section{1) CASE 1:}

When the big bin encounters the dumping yard, which is sensed by the Big bin IR sensor, DC motor-5 of big bin operates and big bin lid will be opened to dump the garbage in the dumping yard.

\section{2) CASE 2:}

When garbage level in big bin reach to the threshold level, big bin level IR sensor gives high as output. Upon receiving high input from the level IR sensor, the big bin directly moves to the dumping yard by ignoring small bins. Once the big bin reaches dumping yard, big bin location sensor output will be high and garbage will be dumped in the dumping yard.

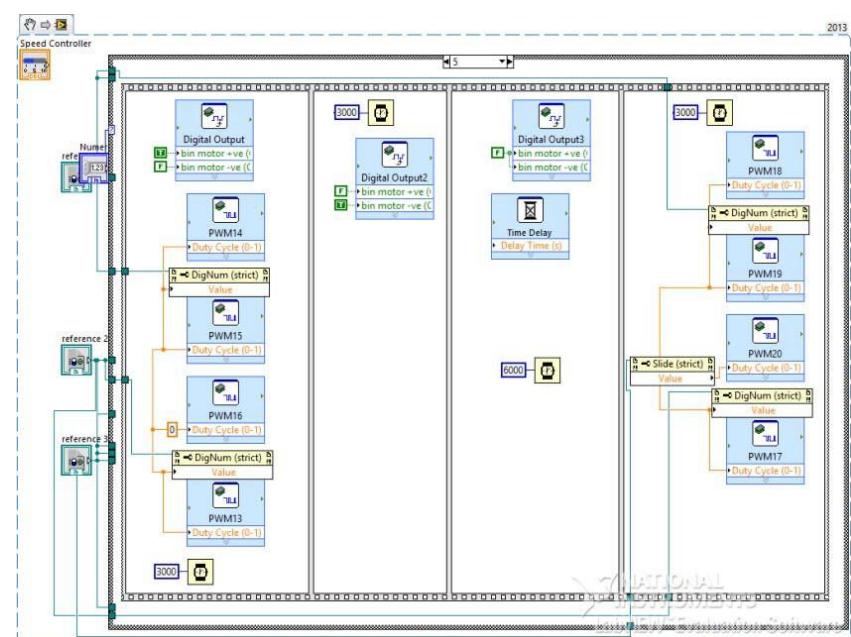

Fig. 13. Big bin encounters dumping yard

\section{CONCLUSION}

Automatic garbage collection and dumping system is an advanced system to eliminate the manual process. Proposed system helps to collect the garbage from small bins by following a black line path carrying a big sized bin and when bin is full or detected dumping yard, it will dump the entire garbage in dumping yard. Proposed system fulfill the task of collecting garbage from certain places and then dispose it at a single place from where garbage will be taken for disposal or process of recycling, thus reduces labour requirement, health hazards. It has wide range of applications in many areas like hospitals, railway stations, bus stations, airport and many public areas where huge amounts of waste is being disposed rapidly in the smaller bins and which require frequent waste disposal. Future work includes different types of garbage to be dumped into different compartments within the garbage collector and also including GPS based navigation system into the garbage collector, so that it can collect and dispose waste among floors instead of being limited to single floor in a building. Level sensors can also be arranged to the small bins, so that, whenever garbage in any one of the small bins reaches to the threshold level, the big bin directly moves to that particular small bin, ignoring other small bins in the path and collect the garbage.

\section{ACKNOWLEDGMENT}

The authors would like to thank management of Vardhaman College of Engineering for allowing us to use Virtual Instrumentation Laboratory and National Instruments hardware to carry out this research. Authors also thank Head of the Department, Electronics and Communication Engineering for supporting us in executing this work.

\section{REFERENCES}

1. Fetulhak Abdurahman, Sileshi Aweke, Chera Assefa, "Automated Garbage Monitoring System using Arduino", IOSR Journal of Computer Engineering, Vol 20, Issue 1, Ver. I (Jan-Feb 2018), pp 64-76.

2. S C V S L S Ravi Kiran, B. Ashwin Kumar, Mohammad Umar, V D S Krishna, K. Karthik, "Implementation of Smart Garbage Monitoring System using IOT", International Journal of Advanced Research in Coputer and Communication Engineering, Vol. 8, Issue 1, January 2019, pp 107-113. 
3. Vedant Dhamde, Ameya Pacholi, Shreyas Ragit, Heena Agarwal, "IOT based Garbage Management System", International Journal of Computer Sciences and Engineering", Vol 6, Issue 5, May 2018, pp 675-680.

4. Vinod J Thomas, Brighty Xaviour, Jeeshma K Georg, "Cleaner Robot", International Journal of Emerging Technology and Advanced Engineering Journal, Vol 5, Issue 12, December 2015.

5. Saravana Kannan G, Sasi Kumar S, Ragavan R, Balakrishnan M, "Automatic Garbage Separation Robot Using Image Processing Technique", International Journal of Scientific and Research Publications, Volume 6, Issue 4, April 2016.

6. Hesham Alsahafi, Majed Almaleky, "Design and Implementation of Metallic Waste Collection Robot”, SEE2014 Zone I Conference, April 3-5, 2014, University of Bridgeport, Bridgpeort, CT, USA.

7. Osiany Nurlansa, Dewi AnisaIstiqomah, Mahendra Astu Sanggha Pawitra, Member, IACSIT "AGATOR (Automatic Garbage Collector) as Automatic Garbage Collector Robot Model" International Journal of Future Computer and Communication, Vol. 3, No. 5, October 2014.

8. Chaomin Luo\& Simon X. Yang Deborah A. Stacey: "Real-time path planning with Deadlock Avoidance of Cleaning Robot", Proceedings of 2003 IEEE International Conference on Robotic.

9. Dr. N. SATHISH KUMAR, B.VIJAYALAKSHMI, R. JENIFERPRARTHANA, A. SHANKAR, Region 10 Conference (TENCON),"IOT Based Smart Garbage alert system using Arduino UNO", 2016.

10. Md. Liakot Ali, Mahbubul Alam, Md. Abu Nayeem Redwanur Rahaman, (2012). "RFID based E-monitoring System for Municipal Solid Waste Management", International Conference on Electrical and Computer Engineering, Pg 474-477.

11. Hannan, M., A., Arebey, M., Basri, H. (2010).“Intelligent Solid Waste Bin monitoring and Management System", Australian Journal of Basicand Applied Sciences, 4(10): 4314-4319, 2010,ISSN 1991- 8178.

12. Twinkle Sinha, K. Mugesh Kumar, P. Saisharan,(2015). "SMART DUSTBIN", International Journal of Industrial Electronics and Electrical Engineering, ISSN: 2347-6982, Volume-3, Issue-5.

13. Rick Bitter, Taqi Mohiuddin, Matt Nawrocki "LabVIEW Advanced Programming techniques" Second Edition, 2000.

14. https://www.ni.com/en-in/shop/select/myRIO-student-embeddeddevice.

15. https://www.arduino.cc/en/Tutorial/HomePage.Smith, T.F., Waterman, M.S.: Identification of Common Molecular Subsequences. J. Mol. Biol. 147, 195--197 (1981).

\section{AUTHORS PROFILE}

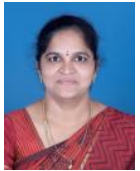

M. Srilatha received her B.Tech (Electronics and Communication Engineering) in 2004 from Jawaharlal Nehru Technological University Hyderabad, M.E.(Digital Systems) in 2010 from Osmania University, Hyderabad. Presently she is pursuing her $\mathrm{Ph}$. D. in the area of Wireless Communications from Osmania University, Hyderabad. Her research interes includes Cognitive Radio, LabVIEW. She has published 15 papers in various International journals and International Conferences.

She is having 15 years of teaching experience and currently working as Assistant Professor in the Department of Electronics and Communication Engineering, Vardhaman College of Engineering, Hyderabad, Telangana State, India from 2012.

She is a member of professional bodies like IEEE, IETE, IAENG, UACEE and SAISE. She can be reached at m.srilatha@vardhaman.org; srilathateli@gmail.com; ma_srilatha2@yahoo.co.in.

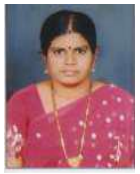

Dr. D. Nagajyothy obtained B.Tech degree in Electronics and Communication Engineering from Nagarjuna University, Guntur in 1999.She received her M.E degree from Osmania University, Hyderabad in 2006. She did her Ph.D program in ANU College of Engineering and Technology, Guntur. At present she is working as Associate professor in the department of Electronics and Communication Engineering, at Vardhaman College of Engineering, Shamshabad, Telangana, INDIA. She actively involved in research and guiding Projects for Post Graduate students in the area of Signal Processing and applications. She has taught a wide variety of courses for UG students and guided several projects. She has published several papers in International Conferences and Journals. She is the member of Professional bodies like IACSIT, SAISE, UACEE, IAENG and IEEE, IETE and ISTE.

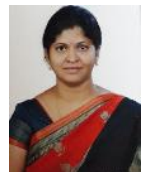

V. Jyothi is working as Assistant Professor in Department of Electronics and Communication Engineering, Vardhaman College of Engineering, Telangana, India. She has over 12 years of academic experience. She guided ARM, Arduino, IoT and Raspberry-Pi based projects for UG as well as PG students. She has published several papers in Internationa Conferences and Journals. She is the member of Professional bodies like IACSIT, SAISE, UACEE, IAENG, IETE and ISTE. 